\title{
CRISIS SANITARIA Y ESTADO DE ALARMA EN ESPAÑA
}

\section{HEALTH CRISIS AND STATE OF EMERGENCY IN SPAIN}

\author{
JUAN FRANCISCO SÁNCHEZ BARRILAO ${ }^{1}$
}

\begin{abstract}
RESUMEN: Este trabajo estudia cómo se ha gestionado la crisis sanitaria del COVID-19 en España, como la posterior crisis social y económica que se ha generado. Y ello, especialmente, al respecto del estado de alarma declarado por el Gobierno español. En este sentido, primero se expone el marco jurídico relativo a la salud pública y a los servicios sanitarios en España, para concretar también en el régimen de excepción previsto por la Constitución española. Luego se presenta el estado de alarma declarado en España por el Gobierno central, así como las medidas más relevantes que ha adoptado con relación a la sanidad, a la limitación de derechos (a fin de evitar contagios) y para otras necesidades sociales y económicas. Por último, se advierten las tensiones políticas que la vigente crisis está generando a nivel social y parlamentario, además de en el plano autonómico y europeo.
\end{abstract}

PAlabras Clave: Crisis sanitaria; COVID-19; estado de alarma; España.

ABSTRACT: This paper studies how the COVID-19 health crisis has been managed in Spain, as well as the subsequent social and economic crisis that has been generated. And this, especially, with respect to the state of emergency declared by the Spanish government. In this sense, it first explains the legal framework relating to public health and health services in Spain, to be specified also in the exception regime provided by the Spanish Constitution. Then the state of emergency declared in Spain by the central government is presented, as well as the most relevant measures it has adopted in relation to health, to the limitation of rights (to avoid contagion) and to other social and economic needs. Finally, the political tensions that the current crisis is generating at the social and parliamentary level, as well as at the regional and European levels, are noted.

KEYWORDS: Health crisis; COVID-19; state of emergency; Spain.

\footnotetext{
${ }^{1}$ Profesor Titular, Departamento de Derecho Constitucional, Universidad de Granada (España). Contato: juanfco@ugr.es.
} 


\section{INTRODUCCIÓN: LA EMERGENCIA SANITARIA DEL COVID-19 EN ESPAÑA}

El 13 febrero de 2020 el Comité Internacional de Taxonomía de Virus daba nombre al virus (SARS-CoV-2) que había originado una nueva epidemia inicialmente localizada, un par de meses antes (diciembre de 2019), en Wuhan (China); esta, y conocida ahora como COVID-19, se desarrollaría como pandemia ya en marzo de 2020 (O.M.S., 11 de marzo) alcanzando a Europa, y especialmente en los primeros momentos a Italia y España, mientras el brote originario daba muestras de control sanitario allí2 . España comenzó a adoptar medidas intensas a nivel estatal con el Real Decreto-Ley 6/2020, de 10 de marzo (por el que se adoptan determinadas medidas urgentes en el ámbito económico y para la protección de la salud pública) ${ }^{3}$, para activarse luego el estado de alarma el 14 de marzo con el Real Decreto 463/2020 (por el que se declara el estado de alarma para la gestión de la situación de crisis sanitaria ocasionada por el COVID-19), y viniéndose a prorrogar hasta el 21 de junio.

En cuanto a la gravedad de la crisis sanitaria originada por el COVID-19 en España (particularmente en esta primera oleada de contagios), esta no ha respondido tanto a la dimensión letal de la enfermedad en sí, aun teniéndola (pero inferior a otras epidémicas), sino al carácter disruptivo de la misma al respecto del sistema sanitario español en su conjunto, ante la posibilidad de su colapso de no haberse contenido o ralentizado el contagio suficientemente ${ }^{4}$; es decir, en su repercusión letal (y ahora de manera mucho más intensa) con relación, y en concreto, a grupos de riesgo ante el COVID-19 (ancianos, enfermos inmunodeprimidos, etc.), como en consideración a otros casos singularmente graves para la salud de las personas (por otras patologías, como por accidentes), que no hubieran podido ser oportuna y adecuadamente atendidos en caso de desplome del servicio sanitario como consecuencia de una arribada masiva de pacientes a los hospitales españoles (habiéndose disparado, entonces, aún más el número de muertes). Así, y a los 15 días de diagnosticarse oficialmente el COVID19 en España, se sumaban más de 11.000 infectados y de 500 fallecidos; solo diez días después, más de 64.000 afectados y 4.800 muertes; y a otros veinte luego, 172.000 enfermos y 18000 decesos $^{5}$.

\footnotetext{
2 Con todo, datos recientes apuntarían a fechas previas de la extensión de la epidemia, al confirmarse enfermos del COVID-19 en Francia ya en diciembre de 2019.

${ }^{3}$ Sin perjuicio de que antes se hubieran adoptado ciertas medidas a nivel autonómico y con carácter local y concreto (p.e., el confinamiento de turistas en un hotel de Tenerife a finales de febrero).

${ }^{4}$ Y ello, además, tras la recesión sufrida en la sanidad pública en España con ocasión de la anterior crisis económica aquí (en razón a los recortes económicos al respecto, como a procesos de privatización de la misma), de modo que se partía desde una debilidad sanitaria mayor de la deseable.

${ }^{5}$ A comienzos de junio (terminando estas páginas), superándose ya los 240.000 diagnosticados y 27.100 muertes (Ministerio de Sanidad). No obstante, se ha de indicar cómo el número total de muertes en España durante este primer período de la pandemia ha superado en más de 47.000 los fallecidos que en relación a años anteriores se daba (según el Instituto Nacional de Estadística); de este modo es que la anterior cifra oficial de muertes por COVID-19 debiera entenderse, a todas
} 
Pero además, y una vez controlado el primer pico de contagios, y habiéndose reforzado (aun con mínimos) los servicios sanitarios (mayo-junio de 2020), queda el proceso de inmunidad e inmunización en grado suficiente (inmunidad de rebaño o de grupo); y hasta que ello se alcance ${ }^{6}$, el riesgo evidente de potenciales retrocesos y nuevas oleadas de la enfermedad que deben ser debidamente contenidos (y/o minimizados) a fin de evitar, otra vez, ulteriores y potenciales desplomes o colapsos de la asistencia sanitaria española. Por otra parte está también la gravísima crisis social y económica que se comienza a sufrir como consecuencia de la paralización (aun temporal) que de gran parte de la actividad pública y privada ha conllevado el estado de alarma en España, y que necesita ser atendida adecuada y públicamente a fin de evitar, ahora, el colapso del entero sistema constitucional. Y por último, claro, están las primeras manifestaciones de eso que se ha llamado nueva normalidad, y que no es sino los cambios que en las formas de las relaciones sociales (pero no solo) está suponiendo el COVID-19, y que de seguro, en mayor o menor grado, vienen para quedarse (así, la distancia social).

\section{EL MARCO NORMATIVO PREVIO ANTE LA CRISIS SANITARIA DEL COVID-19}

La genérica consideración constitucional del Estado español como social y democrático de Derecho (art. 1.1 CE), junto con la más específica de la salud como principio rector de la política social y económica, conlleva no solo el deber de los poderes públicos españoles de promover la protección de la salud como derecho (arts. 43.1 y $53.3 \mathrm{CE}$ ), sino el reconocimiento de la competencia o potestad de estos para «organizar y tutelar la salud pública a través de medidas preventivas», además «de las prestaciones y servicios necesarios» a tales efectos (art. 43.2 CE). Y en este sentido, que la Ley 33/2011, de 4 de octubre, General de Salud Pública establezca «las bases para que la población alcance y mantenga el mayor nivel de salud posible a través de las políticas, programas, servicios, y en general actuaciones de toda índole desarrolladas por los poderes públicos, empresas y organizaciones ciudadanas con la finalidad de actuar sobre los procesos y factores que más influyen en la salud», y con ello prevenir enfermedades «y proteger y promover la salud de las personas, tanto en la esfera individual como en la colectiva» (art. 1 L 33/2011). Tampoco puede olvidarse la estrecha relación constitucional de la salud con la dignidad de la persona (art. 10.1 CE) y con el derecho a la vida y a la integridad física (art. $15 \mathrm{CE}$ ), en particular a la vista de su dimensión objetiva ${ }^{7}$, de modo que ambos conceptos por sí promueven actuaciones de los poderes públicos a fin de su efectiva garantía y protección.

luces, superada (sin perjuicio de cuáles de esas muertes correspondan directa o indirectamente al COVID-19, o efectivamente a otras causas).

${ }^{6}$ A día de hoy tan solo al 5,2 \% de la población, conforme a un estudio sobre seroprevalencia en desarrollo por el Ministerio de Ciencia e Innovación; de el, también, que el número de los contagiados se presuma mayor de lo anteriormente referido.

${ }_{7}$ SSTC: 53/1985, de 11 de abril (FFJ núms. 3 y 4); y 62/2007, de 27 de marzo (FJ núm. 5). 
A su vez es que la salud pública se prevea como límite de derechos y libertades en España conforme la Ley Orgánica 3/1986, de 14 de abril, de Medidas Especiales en Materia de Salud Pública, y el Convenio para la Protección de los Derechos Humanos y de las Libertades Fundamentales (arts. 5.1.e -especialmente-, 8.2, 9.2, 10.2 y $11.2 \mathrm{CEDH}$, a la vista de los arts. 10.2, 94.1.c. y $96 \mathrm{CE}$ ); mas ello, de diversa manera, pues mientras la Ley Orgánica 3/1986 autorizaría concretas medidas a adoptarse (aun indeterminadas de forma abstracta) al respecto de específicas situaciones de grave riesgo para la salud pública (de ahí que dichas medidas deban someterse a autorización o control judicial inmediato, según art. 8.6 L 29/1998, de 13 de julio, reguladora de la Jurisdicción Contencioso-administrativa), el Convenio daría cobertura a limitaciones potencialmente más genéricas (y legales), y ante otras causas restrictivas de derechos (también de interés para estas páginas) como son el orden o la seguridad pública, junto a la protección de los derechos y las libertades de los demás (sin perjuicio, claro, del propio art. $18 \mathrm{CEDH}$ ). Incluso, que las crisis sanitarias se prevean expresamente como causa para la declaración de estados de excepción constitucional en España (como se ha adelantado) ${ }^{8}$, de acuerdo a los artículos 55.1 y 116 de la Constitución, y según su desarrollo conforme la Ley Orgánica 4/1981, de 1 de junio, de los estados de alarma, excepción y sitio (en especial, art. 4.b y c LO 4/1981) ${ }^{9}$.

Al abrigo de todo lo anterior, y desde una visión analógica a su vez de la Ley 8/2011, de 28 de abril, por la que se establecen medidas para la protección de las infraestructuras críticas, estaría la consideración del propio sistema sanitario en España como servicio público esencial cuyo funcionamiento se ha de garantizar para de esta forma evitar amenazas o perturbaciones graves que lo hagan

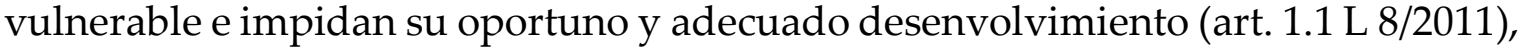
así como su consideración como objeto de la Seguridad Nacional en tanto que, y de acuerdo ahora a la Ley 36/3015, de 28 de septiembre, de Seguridad Nacional: aquel repercute directamente no sólo en el «bienestar de los ciudadanos» (ya, art. $3 \mathrm{~L}$ 36/2015), sino en la garantía del «suministro» de un servicio («y recursos») esencial(es) como es «la seguridad sanitaria» (nuevamente art. 10 L 36/2015, y conforme se acaba de señalar), de modo que, y «sin perjuicio de lo establecido en la normativa reguladora de protección de infraestructuras críticas» (anteriormente referida), las Administraciones Públicas han de asegurar «la disponibilidad de los servicios esenciales» (art. 11.2 L 36/2015); por otra, la seguridad sanitaria es expresamente ámbito de especial interés para la Seguridad Nacional (art. $10 \mathrm{~L}$ 36/2015), llegándose a considerar las epidemias y pandemias como novedoso objeto de la vigente Estrategia de Seguridad Nacional de 2017 (y como uno de los quince ámbitos de especial actuación en el ámbito de la Seguridad Nacional en España); y, finalmente, su repercusión transversal con otros ámbitos de máximo interés para la Seguridad Nacional, como es también la seguridad económica y financiera (otra

\footnotetext{
${ }^{8}$ Y de excepción del propio CEDH, conforme art. 15 del mismo.

${ }^{9}$ De la que se dará cuenta más detallada en el siguiente epígrafe de este trabajo.
} 
vez, art. 10 L 36/2015), tal y como se advierte intensamente no solo a nivel español (según se ha adelantado), sino mundial.

\section{EL DERECHO DE EXCEPCIÓN EN EL DERECHO CONSTITUCIONAL ESPAÑOL}

Conforme lo señalado, la Constitución española específicamente prevé, en sus artículos 55.1 y 116 (y a diferencias de otras de su entorno), supuestos escalonados y cualitativos de suspensión del régimen ordinario constitucional ante graves crisis que afecten a la normalidad constitucional; es decir, la prevención de líneas formales y sustantivas a potenciales medidas con las que superar tales crisis, y sin que quepan ser rebasadas de manera abstracta. El Derecho de excepción supone de este modo, y por esencia, una restricción constitucional en sí del sistema constitucional (en especial al respecto de derechos y libertades, pero no solo) con la que solventar y superar un momento de gravísima crisis para el sistema constitucional; y de ahí (precisamente), de los riesgos que toda excepción constitucional supone (en consecuencia), las limitaciones y controles con las que la propia Constitución española prevé dichos supuestos, en tanto que mayor reto del Estado democrático de Derecho (nuevamente, art. 1.1 CE): atender, desde los fundamentos de la democracia y del constitucionalismo (publicidad, control y garantías), sus crisis internas y externas, frente a la mera eficiencia de cualquier respuesta destinada a tal fin (CRUZ, 1980).

En desarrollo de dicha previsión constitucional, y de su articulación en diversos niveles de intensidad y cualidades en cuanto que alarma, excepción y sitio, la también referida Ley Orgánica 4/1981 desenvuelve normativamente dichos estados al respecto de: sus procedimientos de adopción, con clara preeminencia del Gobierno y con participación del Congreso de los Diputados (si bien con mayor intervención de este conforme la gravedad del estado que se declare); los supuestos o causas que permiten su progresiva activación; las medidas a adoptarse, y los derechos que pueden limitarse y llegar a ser suspendidos; y los límites, especialmente temporales, como los controles a mantenerse y acordarse (art. 1.2 LO $4 / 1981)^{10}$.

De manera muy sintética y al respecto del estado de alarma ${ }^{11}$, este se activa por el Gobierno mediante decreto (art. 6 LO 4/1981) en supuestos de alteraciones graves de la normalidad causadas por catástrofes, calamidades o desgracias públicas, crisis sanitarias (precisamente), paralización de servicios públicos esenciales, y situaciones de desabastecimiento de productos de primera necesidad (art. 4 LO 4/1981); y pudiéndose adoptar medidas relativas (mas sin establecerse una lista cerrada) a la limitación de movimientos, requisas temporales e imposición de

\footnotetext{
${ }^{10}$ Entre otros: nuevamente CRUZ (1981) y (1984), FERNÁNDEZ (1981), LAFUENTE (1989-1990), NAVAS (1997) y BRU (1999).

${ }^{11}$ En torno al estado de alarma y al RD 1673/2010, de 4 de diciembre (por el que se declaró el primer estado de alarma en España con ocasión de una huelga de controladores aéreos): ABA (2011), ENÉRIZ (2011), VIDAL, DELGADO (2011), REQUEJO (2012) y PÉREZ (2012), CASAS (2014) y ALEGRE (2014).
} 
prestaciones personales, intervención y ocupación transitoria de industrias, fábricas, etc. (salvo domicilios privados), racionamiento de servicios o artículos de primera necesidad, adopción de órdenes necesarias para asegurar el abastecimiento de los mercados y el funcionamiento de los servicios esenciales (art. 11 LO 4/1981), además de otras destinadas concretamente a la lucha contra enfermedades (justamente), como intervenciones y movilizaciones de personal (art. $12)^{12}$.

En tal sentido es de interés la Sentencia del Tribunal Constitucional español $83 / 2016$, de 28 de abril $^{13}$, y en la que, tras incidir en la garantía que supone la necesaria intervención del Congreso de los Diputados ante la potencial acción del Gobierno (FJ núm. 7) ${ }^{14}$, reconoce carácter de valor de ley al decreto de su declaración y a su prórroga (ya, ATC 7/2012, de 13 de enero) al venir no solo a establecer el concreto estatuto jurídico del estado de alarma y en cuanto que «legalidad aplicable», sino a desplazar durante este estado «la legalidad ordinaria en vigor» (FJ núm. 10) $)^{15}$.

Con todo, se ha de advertir la dificultad intrínsecamente prospectiva para prever y ordenar (tanto a nivel constitucional, como luego legal) las muy diversas situaciones de extrema, pero de diversa intensidad, que pueden requerir actuaciones de excepción constitucional con las que procurar volver a cierta normalidad constitucional (expresamente, art. 1.1 LO 4/1981). Y de ahí, finalmente, la también relevante proporcionalidad no solo al momento de graduar el estado a declarar, como las medidas a adoptar y los derechos a limitar y suspender (singularizando así la excepción) y su ulterior materialización (otra vez, art. 1.2 LO

\footnotetext{
${ }^{12}$ En cuanto al estado de excepción, este estaría pensado para situaciones en las que el ejercicio de derechos y libertades, el funcionamiento de las instituciones democráticas, el de los servicios públicos esenciales, «o cualquier otro aspecto del orden público, resulten tan gravemente alterados que el ejercicio de las potestades ordinarias fuera insuficiente para restablecerlo y mantenerlo» (art. 13.1 LO 4/1981); para su declaración el Gobierno requiere de autorización del Congreso (arts. 13.2 y 3, y 14 LO 4/1981), y las medidas a adoptarse permiten la suspensión de determinados derechos y libertades fundamentales, si bien manteniéndose siempre ciertas garantías (arts. 16, 17, 18, 20, 21, 22, 23, 24, 26, 29, 30 LO 4/1981). Y ya el estado de sitio, que ha de adoptarse por el Congreso (a instancia del Gobierno) solo cuando se produzca o amenace «una insurrección o acto de fuerza contra la soberanía o independencia de España, su integridad territorial o el ordenamiento constitucional, que no pueda resolverse por otros medios» (art. 32.1 LO 4/1981); en este estado cabe la suspensión de más derechos (art. 32.3 LO 4/1981), y permite una mayor intervención de las Fuerzas Armadas en la gestión de la crisis (arts. 33, 34, 35 y 36 LO 4/981).

${ }^{13}$ Relativa a un recurso de amparo que encuentra causa en el referido RD 1673/2010, el ulterior Acuerdo del Consejo de Ministros de 14 de diciembre de 2010 solicitando del Congreso autorización para su prórroga, y el RD 1717/2010, de 17 de diciembre, por el que finalmente se prorroga. Tras la STC 83/2016: VILLAR (2018), ÁLVAREZ (2016) y GARRIDO (2017).

${ }^{14}$ Para especificar después en la exclusiva potestad del Gobierno, mediante decreto, de declarar el estado de alarma y al Congreso en su prórroga (FJ núm. 8).

${ }^{15} \mathrm{Y}$ «en la medida en que viene a excepcionar, modificar o condicionar durante ese periodo la aplicabilidad de determinadas normas, entre las que pueden resultar afectadas leyes, normas o disposiciones con rango de ley, cuya aplicación puede suspender o desplazar».
} 
4/1981), sino con relación al mismo régimen constitucional de la excepción, de forma que concretas circunstancias (siempre de gran intensidad y gravedad) puedan llevar a excepcionar legítimamente el propio régimen de excepción a fin superar la crisis (FERNÁNDEZ, 2020), como se advierte en Derecho comparado (CRUZ, 2017).

\section{EL REAL DECRETO 463/2020, POR EL QUE SE DECLARA EL ESTADO DE ALARMA PARA LA GESTIÓN DE LA SITUACIÓN DE CRISIS SANITARIA OCASIONADA POR EL COVID-19, Y SUS ULTERIORES PRÓRROGAS Y DESARROLLOS}

Según lo adelantado, y de acuerdo al marco jurídico recién presentado, a través del Real Decreto 463/2020 el Gobierno español vino a declarar el estado de alarma al respecto de la gestión de la gravísima crisis sanitaria generada por el COVID-19 (14 de marzo); y ello, en principio, en clara correspondencia con las situaciones de peligro sanitario que prevé la Ley Orgánica 4/1981 (conforme se ha señalado).

A tales efectos, el Real Decreto 463/2020, y previa justificación del mismo: declara el estado de alarma en razón a la referida crisis sanitaria (art. 1); determina el ámbito territorial, extendiéndolo a nivel nacional (art. 2), y su duración, «de quince días naturales» (art. 3); señala al propio Gobierno como autoridad competente (art. 4.1), a algunos Ministerios como competentes delegados (art. $4.2 \mathrm{y}$ 3), además de activar ya cierta estructura de la Seguridad Nacional (art. 4.4) y requerir la colaboración de los ciudadanos y del resto de autoridades (art. 5), sin perjuicio de que el resto de Administraciones Públicas conserven sus competencias en la gestión ordinaria de sus servicios a fin de «adoptar las medidas que estime necesarias en el marco de las órdenes directas de la autoridad competente a los efectos del estado de alarma» (art. 6); determina las medidas a adoptarse en relación a las personas, entre las que se incluyen comprobaciones por agentes de seguridad sobre estas, bienes, vehículos, locales y establecimientos (art. 5.2), limitaciones de la libertad de circulación de las mismas (art. 7.1) y vehículos (art. 7.2, 3 y 4), requisas temporales y prestaciones personales obligatorias (art. 8), y medidas de contención en el ámbito educativo (art. 9), en el de la actividad comercial, equipamientos culturales, establecimientos y actividades recreativos, actividades de hostelería y restauración y otras adicionales (art. 10), y en relación con los lugares de culto y con las ceremonias civiles y religiosas (art. 11); además se adoptan otras medidas dirigidas a reforzar el Sistema Nacional de Salud en todo el territorio nacional (art. 12) y el aseguramiento del suministro de bienes y servicios necesarios para la protección de la salud pública (art. 13), como otras al respecto de transportes (art. 14), abastecimiento alimentario (art. 15), tránsito aduanero (art. 16), garantía de suministro de energía eléctrica, productos derivados del petróleo y gas natural (art. 17), y sobre otros operadores críticos de servicios esenciales (art. 18) y medios de comunicación de titularidad pública y privada (art. 19); se hace referencia al régimen sancionador por incumplimiento o resistencia a las órdenes de las autoridades competentes en el estado de alarma (art. 20); y finaliza con otras referencias con relación al personal extranjero acreditado como miembro de 
misiones diplomáticas (disp. adic. $1^{\mathfrak{a}}$ ), la suspensión de plazos procesales (disp. adic. $2^{\mathrm{a}}$ ), administrativos (disp. adic. $3^{\mathrm{a}}$ ) y cualesquiera otras acciones y derechos (disp. adic. $4^{\mathrm{a}}$ ), al carácter de agente de la autoridad de los miembros de las Fuerzas Armadas (disp. adic. 5a), a la ratificación de las medidas adoptadas por las autoridades competentes de las Administraciones Públicas (disp. final 1aㅡ), así como una habilitación normativa (disp. final $2^{\mathrm{a}}$ ) y su inmediata entrada en vigor (disp. final $3^{\mathrm{a}}$ ).

En cuanto a otras disposiciones adoptadas en España en desarrollo de las anteriores ${ }^{16}$, cabe distinguir dos ejes, uno temporal y otro material. Respecto al primero, se hace referencia al paso del tiempo y por tanto al cambio de escenarios que condicionan el estado de alarma, como a la propia consideración provisional del mismo. Así, la alarma ha sido prorrogada cada quince días, hasta llegar al 21 de junio $^{17}$, además de haberse visto modificada conforme a las mayores o menores necesidades, o distintas circunstancias, que han venido dándose en cada momento: desde el inicial confinamiento y ulterior casi cierre total de actividades públicas y privadas (en particular, desde el 30 de marzo al 9 de abril), a la progresiva, transversal y asimétrica desescalada luego en cuatro fases y orientadas a una nueva normalidad de control del riesgo del COVID-19 ${ }^{18}$. Y con relación a la dimensión sustantiva de las medidas adoptadas en España durante el estado de alarma, es que estas quepan integrarse en tres planos ahora, según que estén destinadas a la asistencia sanitaria, a evitar el contagio, y a atender, finalmente, las necesidades sociales y económicas que han ido surgiendo a la sombra de lo anterior.

Respecto a las primeras, ya se ha visto en la recién presentación del Real Decreto 463/2020 la adopción de diversas medidas destinadas a reforzar el sistema sanitario a nivel hospitalario y farmacéutico (e incluso antes, con el referido RDL 6/2020), como luego otras de tipo residencial incluso (llegándose a levantar hospitales de campaña, o a medicalizarse hoteles y residencias de ancianos), o en relación con los propios procesos de asistencia médica mediante nuevos protocolos de atención y seguimiento a los enfermos, y de la procura del mismo material sanitario necesario

\footnotetext{
${ }^{16}$ De las que, dado su gran número (de modo que su simple enumeración nos llevaría a exceder ya el límite de páginas que se nos ha dado para este trabajo), no se va a dar cuenta detallada.

${ }_{17}$ Así, y tras RD 463/2020: RD 476/2020, de 27 de marzo; RD 487/2020, de 10 de abril; RD 492/2020, de 24 de abril; RD 514/2020, de 8 de mayo; RD 537/2020, de 22 de mayo; y RD 555/2020, de 5 de junio.

${ }^{18}$ Fundamentalmente, Plan para la transición hacia una nueva normalidad, de 28 de abril de 2020 (Consejo de Ministros), y por el que se establece los principales parámetros e instrumentos para la consecución de la normalidad, sin perjuicio de ulteriores modificaciones, como (p.e.): Orden SND/399/2020, de 9 de mayo; Orden TMA/400/2020, de 9 de mayo; Orden SND/414/2020, de 16 de mayo; Orden SND/487/2020, de 1 de junio; Orden SND/507/2020, de 6 de junio; y RDL 21/2020, de 9 de junio, de medidas urgentes de prevención, contención y coordinación para hacer frente a la crisis sanitaria ocasionada por el COVID-19.
} 
(en especial compra y fabricación de respiradores automáticos, y garantía de abastecimiento de suministros y equipos de protección individual) ${ }^{19}$.

En cuanto a las medidas adoptadas para evitar la propagación del COVID-19, y desde el referido Real Decreto 463/2020 (y sus prórrogas y modificaciones), estas se centran fundamentalmente en la restricción de actividades y derechos a fin de limitar el contacto entre personas, al punto de haberse establecido un confinamiento de facto de la entera población en España. Así, las medidas restrictivas y drásticas de circulación (en principio, art. $19 \mathrm{CE}$ ) que ha conllevado en la práctica la permanencia obligatoria de todos en sus hogares y similares (residencias, etc.), y al margen de su alcance de acuerdo a las excepciones establecidas (art. 7.1 RD 463/2020) ${ }^{20}$, además de repercutir en otros derechos y libertades no directamente limitados, como son los de reunión y manifestación (art. 21.1 CE, sin perjuicio de su legítima limitación de acuerdo a arts. 21.2 CE y 10 LO 9/1983, de 15 de julio, reguladora del Derecho de Reunión, y al respecto de la LO $3 / 1986)^{21}$, han terminado por afectar a la propia libertad personal o deambulatoria (art. 17.1 CE) ${ }^{22}$; no en vano, y al margen de la jurisprudencia constitucional entorno a situaciones asimilables al confinamiento domiciliario que supone el Real Decreto $463 / 2020^{23}$, la rotundidad con la que se buscó que todos permaneciéramos en domicilio (en sentido amplio) ${ }^{24}$ vino a aproximar tal situación a una casi suspensión

19 Por cierto, con no pocos problemas durante el primer mes, dada la altísima demanda que en tal momento se da a nivel mundial (saturándose la demanda), como por supuestos de entrega de material defectuoso o retenidos.

20 «1. Durante la vigencia del estado de alarma, las personas únicamente podrán circular por las vías o espacios de uso público para la realización de las siguientes actividades, que deberán realizarse individualmente, salvo que se acompañe a personas con discapacidad, menores, mayores, o por otra causa justificada:

a) Adquisición de alimentos, productos farmacéuticos y de primera necesidad, así como adquisición de otros productos y prestación de servicios de acuerdo con lo establecido en el artículo 10.

b) Asistencia a centros, servicios y establecimientos sanitarios.

c) Desplazamiento al lugar de trabajo para efectuar su prestación laboral, profesional o empresarial.

d) Retorno al lugar de residencia habitual.

e) Asistencia y cuidado a mayores, menores, dependientes, personas con discapacidad o personas especialmente vulnerables.

f) Desplazamiento a entidades financieras y de seguros.

g) Por causa de fuerza mayor o situación de necesidad.

h) Cualquier otra actividad de análoga naturaleza».

${ }^{21}$ Cfr. NOGUEIRA (2020, p. 30).

${ }_{22}$ Conforme, y p.e., STC 85/2019, de 19 de junio (FJ núm. 5).

${ }^{23}$ Si bien en el ámbito sancionador, SSTC 31/1985, de 5 de marzo, 61/1995, de 19 de marzo o 208/2000, de 24 de julio.

${ }^{24}$ Bajo control policial de tan estricta limitación de la circulación y so pena de la correspondiente sanción en caso de infracción (arts. 5.220 RD 463/2020, y a su amparo art. 4.1 Orden INT/226/2020, de 15 de marzo (por la que se establecen criterios de actuación para las Fuerzas y Cuerpos de 
de la libertad de movimiento (al margen de los supuestos permitidos, claro ${ }^{25}, \mathrm{y}$ acercándose entonces, intensamente, al estado de excepción (arts. 55.1 CE, y 13.2.a LO 4/1981 ${ }^{26}$.

Ello es un problema, pues, de acuerdo al Tribunal Constitucional, «la declaración del estado de alarma no permite la suspensión de ningún derecho fundamental (art. 55.1 CE, contrario sensu), aunque sí la adopción de medidas que pueden suponer limitaciones o restricciones a su ejercicio», como es «la limitación de la circulación o permanencia de personas o vehículos en lugares determinados o condicionarlas al cumplimiento de ciertos requisitos» (STC 83/2016-FJ núm. 8, in fine-), lo que, según acabamos de apuntar, podría haberse excedido al respecto del escenario de confinamiento domiciliario en el que efectivamente nos hemos

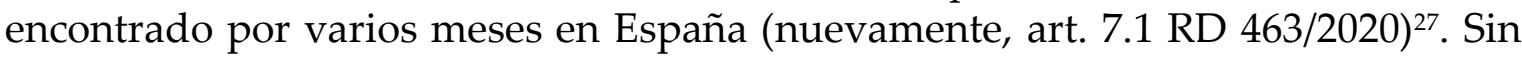
embargo, el presupuesto de gravísima alteración del orden público que autoriza tanto la declaración del estado específico de excepción (otra vez, art. 13.1 LO 4/1981), como en relación con el resto de medidas que dicho estado permite (en cuanto que orientadas al mantenimiento del orden público; especialmente, arts. 16, 17 y 18 LO 4/1981), no se ha dado hasta ahora ${ }^{28}$. Y así parecería haberlo entendido el propio Tribunal Constitucional en un Auto de 30 de abril de 202029, cuando, sin

Seguridad en relación con el Real Decreto 463/2020, de 14 de marzo, por el que se declara el estado de alarma para la gestión de la situación de crisis sanitaria ocasionada por el COVID-19), además, claro, de la LO 4/2015, de 30 de marzo, de Protección de la Seguridad Ciudadana). Vid. AMOEDOSOUTO (2020).

${ }^{25}$ De interés, acerca de la dificultad de distinción entre la limitación de los derechos y su suspensión, COTINO (2020).

${ }^{26}$ Si la libertad de circulación supone la libertad de ir de un lugar a otro pasando por uno u otro espacio público, de manera que su limitación puede afectar tanto al destino como al camino, incluso a la forma del desplazamiento, la libertad deambulatoria, además de presupuesto de lo anterior (el poder partir), permitiría simplemente salir de un lugar, de modo que su efectiva limitación viene a impedirlo, como así habría venido finalmente a suceder en España a la vista de la obligada y genérica permanencia en los domicilios salvo las concretas excepciones normativamente previstas (y referidas).

27 Así, ya, Recurso de inconstitucionalidad núm. 2054-2020 (y admitido a trámite el TC por providencia de 6 de mayo).

28 El estado de excepción parece estar pensado para crisis en las que la normalidad constitucionalidad ha sido gravemente alterado por la acción de toda o parte de la ciudadanía (o terceros), al punto de que los instrumentos ordinarios políticos y jurídicos resultan insuficientes para restablecer y normalizar la situación; y a tales efectos, que las medidas específicamente pensadas para el estado de excepción estén precisamente orientadas a restablecer dicho orden público artificialmente alterado. Mientras, la extrema gravedad que supone la crisis sanitaria del COVID-2019 al respecto del servicio esencial sanitario, sí que vendría a justificar, y desde la referida proporcionalidad abstracta de la excepción constitucional, el señalado confinamiento domiciliario que a la postre se ha dado.

${ }^{29}$ Por la que inadmitió un recurso de amparo de un sindicato contra una sentencia judicial que desestimó, precisamente, su solicitud de manifestación el pasado día 1 de mayo. 
perjuicio de no resolver sobre la constitucionalidad de tal declaración de alarma expresamente, sí que viene a presuponerla de manera preliminar ${ }^{30}$.

Por otra parte, y superándose la anterior situación o fase de confinamiento, se mantienen, no obstante (y en progresivas fases de desescalada, según se ha adelantado), medidas restrictivas de grupos máximos de personas y en garantía de distancias mínimas entre estas (y dependiendo del tipo de actividades y situaciones a darse), incluso de vetos (en el caso de ancianos), además de la obligatoriedad generalizada ahora del uso de mascarillas en lugares públicos cerrados, como en espacios abiertos en los que no sea posible mantener las referidas distancias mínimas $^{31}$.

Y finalmente toda una batería de medidas destinadas a atender necesidades sociales y económicas surgidas a la sombra del referido confinamiento y la paralización de casi la total actividad pública y privada (económica). En tal sentido, y por ejemplo: mejoras en la protección de trabajadores aislados y/o infectados, y en la cobertura por desempleo; refuerzo de derechos de los trabajadores en materia de conciliación laboral; limitación de despidos, y previsión de permisos retribuidos recuperables para trabajadores que no prestaran servicios esenciales desde el 30 de marzo al 9 de abril (cuando la suspensión de actividad fue total, a salvo de servicios declarados expresamente como esenciales); subsidios extraordinarios temporales para empleadas del hogar y para trabajadores con contrato temporal; suspensión de desahucios, moratorias de alquileres, y micro-créditos para inquilinos; moratoria hipotecaria en caso personas en situación de vulnerabilidad económica por el COVID-19, así como suspensión de las obligaciones derivadas de los contratos de crédito sin garantía hipotecaria (durante tres meses); aplazamiento del pago alquiler de locales comerciales; becas comedor para la alimentación de niños en situación de vulnerabilidad; suministro de agua, energía eléctrica y gas natural

\footnotetext{
${ }^{30}$ Otra cosa es la necesidad, adecuación, razonabilidad y específica proporcionalidad ahora de todas y cada una de las tan intensas medidas adoptadas en el vigente estado de alarma a fin de evitar, precisamente, dicho contagio generalizado (además de su contención y la atención sanitaria de los enfermos), como, y no obstante (y a la luz de lo anterior), cierta restricción interpretativa de la normativa sancionadora aplicable, por cuanto que fundamentalmente dirigida (según se ha advertido) a evitar situaciones de riesgo de contagio.

${ }^{31}$ Así, y progresivamente (y de manera cambiante): Resolución de 14 de abril de 2020, de la Dirección General de Transporte Terrestre, complementaria de la Resolución de 2 de abril de 2020, por la que se dictan instrucciones para la distribución de las mascarillas en el ámbito del transporte terrestre; Orden TMA/384/2020, de 3 de mayo, por la que se dictan instrucciones sobre la utilización de mascarillas en los distintos medios de transporte y se fijan requisitos para garantizar una movilidad segura de conformidad con el plan para la transición hacia una nueva normalidad; Orden SND/422/2020, de 19 de mayo, por la que se regulan las condiciones para el uso obligatorio de mascarilla durante la situación de crisis sanitaria ocasionada por el COVID-19; y Orden TMA/424/2020, de 20 de mayo, por la que se modifican la Orden TMA/384/2020 por la que se dictan instrucciones sobre la utilización de mascarillas en los distintos medios de transporte y se fijan requisitos para garantizar una movilidad segura de conformidad con el plan para la transición hacia una nueva normalidad. También, el referido RDL 21/2020 (en especial, art. 6).
} 
a consumidores vulnerables; prórroga automática del plazo de vigencia del bono social eléctrico; protección al consumidor en los contratos de compra venta y suspensión de plazos para devolución de productos; aplazamiento bonificado en el pago impuestos y reducción de pagos fraccionados en materia tributaria (primer trimestre de 2020); moratoria de cotizaciones sociales y pago de deudas a la Seguridad Social para los autónomos, y prestación extraordinaria por cese de actividad para estos; medidas de flexibilización de los procedimientos de suspensión de contratos y reducción de jornada por causa de fuerza mayor; una línea de avales para la cobertura por cuenta del Estado de la financiación otorgada por entidades financieras a empresas y autónomos, y de financiación para atender a las empresas y autónomos del sector turístico y actividades conexas afectados por el COVID-19; y la previsión, finalmente, de una renta mínima o ingreso mínimo vital (si bien proyectada con una voluntad de permanencia, y por tanto más allá de mera medida coyuntural al respecto de la vigente crisis) ${ }^{32}$.

\section{LA ORDENACIÓN TERRITORIAL DE LA CRISIS DEL COVID-19 EN ESPAÑA: ESTADO, COMUNIDADES AUTÓNOMAS Y UNIÓN EUROPEA}

Pero la declaración del estado de alarma no solo ha afectado a la ciudadanía, sino también a la ordenación territorial del poder en España, y especialmente al respecto de las competencias en materia de sanidad que ostentan y ejercen las Comunidades Autónomas (conforme arts. 147.2.d, 149.1.16 y 149.3 CE). En tal sentido, el Real Decreto 463/2020 señaló al Gobierno central como autoridad competente y a ciertos Ministerios como autoridades delegadas (art. 4.1, 2 y 3), frente a las Comunidades (art. 6). Sin perjuicio de la constitucionalidad de tal excepcionalidad de la distribución constitucional del poder ${ }^{33}$, entendemos ${ }^{34}$, y de cómo el Real Decreto 463/2020 garantizara expresamente que cada Administración conservare, no obstante, las competencias que le otorga la legislación «en la gestión ordinaria de sus servicios para adoptar las medidas que estime necesarias en el marco de las órdenes directas de la autoridad competente» (art. 6, y sin perjuicio de lo establecido en los arts. 4 y 5) ${ }^{35}$, es que, finalmente, se haya venido a generar

\footnotetext{
${ }^{32}$ Mas sin perjuicio, claro, de su oportunidad en este momento; a tales efectos, vid. RDL 20/2020, de 29 de mayo, por el que se establece el ingreso mínimo vital.

33 Ya, VELASCO (2020).

${ }^{34} \mathrm{Sin}$ perjuicio de las diferencias existente entre las medidas adoptadas por el Gobierno por el RD 463/2020 (y al amparo del art. 116 CE y LO 4/1981) al respecto de todas las Comunidades Autónomas y las medidas que puede conllevar la activación del art. 155 CE con relación a una concreta Comunidad Autónoma (para el caso de graves incumplimiento de obligaciones constitucionales), es que la STC 89/2019, de 2 de julio, haya reconocido cierta relación (FJ núm. 2.b).

${ }^{35}$ Otra cosa hubiera sido el que la declaración del estado de alarma se hubiera declarado por el Gobierno de forma limitada al territorio (o a parte) de una Comunidad Autónoma (incluso a instancia de esta, conforme art. 5 LO 4/1981), de modo que, y ahora sí (STC 83/2016 -otra vez, FJ núm. 8-), el Presidente de ella debiera resultar como autoridad competente por delegación del Gobierno (art. 7 LO 4/1981).
} 
una progresiva tensión entre el Estado central y las Comunidades Autónomas. Y ello no solo al momento de la declaración y del ulterior desarrollo de la alarma y la gestión llevada a cabo por el Gobierno central, sino al respecto de la desescalada todavía planificada y gestionada por el Gobierno, y en razón a la asimetría territorial y temporal con la que esta se ha llevado a cabo $^{36}$, no obstante cierto relajamiento para la última fase del estado de alarma al venir las Comunidades a cobrar mayor protagonismo ${ }^{37}$.

Por otra parte, además, se ha de tener en mente la integración de España en la Unión Europea, y con ello la recíproca incidencia de la gestión de la crisis del COVID-19 con relación al proceso de integración en Europa. Así, y a la vista de la limitación estatal del endeudamiento público (art. 135 CE) ante la Unión (Pacto de Estabilidad y Crecimiento), la propuesta de la Comisión Europea, el 20 de marzo, de suspender las reglas presupuestarias de los Estados miembros a fin precisamente de aumentar su gasto público ante la crisis del COVID-19; y de otro, además, las dificultades y enfrentamientos que en el seno de la Unión Europea se están dando en relación con una adecuada articulación de la necesaria solidaridad que entre los Estados se debería de alcanzar en materia de salud pública (en base a los arts. 3.3 y 24.3 TUE, y 4.2.k, 6.a, 9 y, particularmente, 222 TFUE), en especial con los más afectados (como es el caso de España o Italia $)^{38}$.

\section{CONCLUSIONES}

El apretado repaso que hemos planteado de la emergencia sanitaria del COVID19 en España, de la declaración y la gestión del estado de alarma, como de otras medidas adoptadas aquí, dificulta muy mucho plantear un análisis riguroso y detallado de todas y cada una de las cuestiones constitucionales que ello supone; y esto, todavía más, desde la referida abstracción y discrecionalidad con la que se prevén los estados de excepcionalidad constitucional, de manera que la

\footnotetext{
${ }^{36}$ Así, p.e., recurso contencioso-administrativo ante el Tribunal Supremo por la Comunidad de Madrid al respecto de una segunda negativa del Gobierno central con relación al paso de esta Comunidad de la fase 0 a la fase 1 de la desescalada.

${ }^{37}$ Otra vez RDL 21/2020, arts. 2.3, 3, 7.3, 10.2, 24, 25, 27.3, 29, 30, disp. adic. sexta 2, y disp. final segunda.

${ }_{38}$ Con todo, cabe advertir cómo en el seno de la Unión Europea: se han tomado medidas en apoyo a la investigación para el tratamiento, el diagnóstico y las vacunas, así como de tipo directo al sector sanitario de la Unión (Instrumento para la Prestación de Asistencia Urgente); se han adoptado directrices médicas para los Estados miembros; se ha potenciado la disponibilidad de equipos de protección individual (producción, importación, etc.); se han adoptado medidas relativas a fronteras y movilidad; y se han aprobado ayudas económicas (en orientación económica para los Estados miembros, en movilización del presupuesto de la UE y del Banco Europeo de Inversiones para salvar puestos de trabajo y apoyar a las empresas afectadas por la crisis, y otras iniciativas de Inversión en Respuesta al Coronavirus), además de anunciarse (al momento de ultimas estas páginas) un Plan Europeo de Recuperación de 750.000 millones de euros (con dos terceras partes a fondo perdido, y el otro tercio como préstamos), si bien sujetos a condiciones en el gasto (pudiendo corresponder a España 75.000 millones de ellos).
} 
proporcionalidad no solo juega ante las medidas adoptadas por aquel (como su ulterior implementación y realización, conforme art. 1.2 LO 4/1981) ${ }^{39}$, sino del mismo entendimiento de la excepcionalidad constitucional en sí (según se ha señalado $)^{40}$.

Tampoco el enfrentamiento político progresivamente desarrollado entre el Estado y algunas Comunidades Autónomas (conforme lo apuntado), como a nivel interno del primero entre el Gobierno de coalición que gobierna y el resto de las fuerzas políticas con representación parlamentaria (pues no solo afecta a la oposición, sino a socios iniciales de aquel), ayuda a un juicio sereno hoy sobre las medidas adoptadas. Y ello, todavía más, al haberse extendido tal enfrentamiento a una parte de la sociedad civil no solo por motivos obvios (el elevadísimo número de muertes e infectados, como por el aumento del paro (aun con carácter temporal), la reducción de ingresos económicos, las quiebras y cierres empresariales, las limitaciones de derechos, el retraso en la materialización de algunas ayudas, las nuevas incertidumbres que se abren para los próximos meses, etc.), sino por su amplificación a instancia de los nuevos populismos que prenden en nuestras democracias (en particular los de corte nacionalista); esto agranda el conflicto social, político e incluso jurídico ${ }^{41}$, al punto de originar auténticos riesgos de radicalización y desafección constitucional, a la vez que plantea otros recorridos, como es en la propia integración europea (especialmente ante las deficiencias con las que la solidaridad europea se manifiesta, y más tras la deslegitimación que ya se arrastra de la anterior crisis económica).

Tales desencuentros, por último, ponen a su vez a prueba la misma gestión democrática de riesgos y crisis en un mundo cada vez más complejo y cambiante; y es que el pluralismo que caracteriza todavía constitucionalmente las democracias (expresamente art. 1.1, in fine, CE), con su innato y natural conflicto, se ve artificialmente acosado por la supuesta eficiencia de sistemas políticos que vienen a negarlo. Propuestas antidemocráticas así, por iliberales o autoritarias, ganan de este modo adeptos desde una pseudotransversalidad científica, cuando la misma ciencia (y la tecnología), sin embargo, nos abre a nuevas incertezas (y amenazas); y todo ello, especialmente, en estos momentos de reconstrucción de una normalidad asechada todavía por el COVID-19.

${ }^{39}$ Cfr. ÁLVAREZ (2020, p. 8).

40 Además, un juicio a priori y genérico de la legitimidad del RD 463/2020 supondría enfrentarlo no ya a la CE en su conjunto, como a la LO 4/1981 (específicamente), sino al resto del bloque legal vigente (y, por tanto, más allá del referido a la crisis sanitaria) al respecto de las muy diversas cuestiones planteadas y abiertas por aquel. Y ello no solo porque el desplazamiento por el RD $463 / 2020$ de «la legalidad ordinaria en vigor», excepcionando, modificando o condicionando normas legales (recordemos, STC 83/2016 -FJ núm. 10-), requiera estar justificado conforme a los arts. 55.1 y 116 CE y LO 4/1981, sino porque también la legalidad vigente ordinaria (más arriba indicada) cabe que impulse, dando cobertura jurídica, a medidas contenidas en el RD 463/2020 (p.e., las reseñadas LO 3/1986, L 33/2011 o L 36/3015, como la LO 4/2015, entre otras).

${ }^{41}$ En este sentido, p.e., y al momento de escribir estas páginas, el Tribunal Supremo acumula ya más de 40 denuncias y querellas al Gobierno por la gestión del COVID-19. 


\section{BIBLIOGRAFÍA}

ABA CATOIRA, Ana. El estado de alarma en España. Teoría y Realidad Constitucional. N. 28, 2011.

ALEGRE ÁVILA, Juan Manuel. Una nota a propósito de los estados de alarma, excepción y sitio: la declaración gubernamental como acto político y la autorización/declaración parlamentaria como acto sin valor de ley. Revista Española de Derecho Administrativo. N. 163, 2014.

ÁLVAREZ GARCÍA, Vicente. El coronavirus (COVID-19): respuestas jurídicas frente a una situación de emergencia sanitaria. El Cronista del Estado Social y Democrático de Derecho. N. 86-87, 2020.

ÁLVAREZ VÉLEZ, María Isabel. Sistema de fuentes del Derecho y estado de alarma: la STC 83/2016, de 28 de abril. Asamblea: Revista Parlamentaria de la Asamblea de Madrid. N. 34, 2016.

AMOEDO-SOUTO, Carlos-Alberto. Vigilar y castigar el confinamiento forzoso. Problemas de la potestad sancionadora al servicio del estado de alarma sanitaria. El Cronista del Estado Social y Democrático de Derecho. N. 86-87, 2020.

BRU PERAL, Eva María. Estados de alarma, excepción y sitio. Derechos y Libertades: Revista del Instituto Bartolomé de las Casas. N. 7, 1999.

CASAS BAAMONDE, Mara Emilia. Huelga en servicios esenciales para la comunidad y responsabilidad política. Y sobre la declaración del estado de alarma por causa de huelga. Revista Jurídica de Catalunya. V. 113, n. 3, 2014.

COTINO HUESO, Lorenzo. Los derechos fundamentales en tiempos del coronavirus. Régimen general y garantías y especial atención a las restricciones de excepcionalidad ordinaria. El Cronista del Estado Social y Democrático de Derecho. N. 86-87, 2020.

CRUZ VILLALÓN, Pedro. El estado de sitio y la Constitución: la constitucionalización de la protección extraordinaria del Estado (1789-1878). Madrid: Centro de Estudios Constitucionales, 1980.

CRUZ VILLALÓN, Pedro. El nuevo derecho de excepción (Ley Orgánica 4/1981, de 1 de junio). Revista Española de Derecho Constitucional. N. 2, 1981. 
CRUZ VILLALÓN, Pedro. Entre proporcionalidad e identidad: Las claves de la excepcionalidad en el momento actual. Revista de Derecho Constitucional Europeo. N. 27, 2017.

CRUZ VILLALÓN, Pedro. Estados excepcionales y suspensión de garantías. Madrid: Tecnos, 1984.

ENÉRIZ OLAECHEA, Francisco Javier. La declaración del estado de alarma para la normalización del transporte aéreo. Revista Aranzadi Doctrinal. N. 6, 2011.

FERNÁNDEZ DE CASADEVANTE MAYORDOMO, Pablo. El derecho de emergencia constitucional en España: hacia una nueva taxonomía. Revista de Derecho Político. N. 107, 2020.

FERNÁNDEZ SEGADO, Francisco. La Ley Orgánica de los estados de alarma, excepción y sitio. Revista de Derecho Político. N. 11, 1981.

GARRIDO LÓPEZ, Carlos. Naturaleza jurídica y control jurisdiccional de las decisiones constitucionales de excepción. Revista Española de Derecho

Constitucional. N. 110, 2017.

LAFUENTE BALLE, José María. Los estados de alarma, excepción y sitio (I) y (II), Revista de Derecho Político. N. 30-31, 1989-1990.

NAVAS CASTILLO, Antonia. El Tribunal Constitucional en la declaraciónautorización de los estados de alarma, excepción y sitio. In: Parlamento y Justicia Constitucional: IV Jornadas de la Asociación Española de Letrados de Parlamentos, Pamplona: Aranzadi, 1997.

NOGUEIRA LÓPEZ, Alba. Confinar el coronavirus. Entre el viejo Derecho sectorial y el Derecho de excepción. El Cronista del Estado Social y Democrático de Derecho. N. 86-87, 2020.

PÉREZ SOLA, Nicolás. Los estados de alarma, excepción y sitio: la primera declaración del estado de alarma en aplicación de las previsiones constitucionales. In: Constitución y democracia. Ayer y hoy: libro homenaje a Antonio Torres del Moral (II), Madrid: Universitas, 2012.

REQUEJO RODRÍGUEZ, Paloma. Teoría vs. práctica del Estado de alarma en España. In: Constitución y democracia. Ayer y hoy: libro homenaje a Antonio Torres del Moral (II). Madrid, Universitas, 2012. 
VELASCO CABALLERO, Francisco. Estado de alarma y distribución territorial del poder. El Cronista del Estado Social y Democrático de Derecho. N. 86-87, 2020.

VIDAL PRADO, Carlos; DELGADO RAMOS, David. Algunas consideraciones sobre la declaración del estado de alarma y su prórroga. Revista Española de Derecho Constitucional. N. 92, 2011.

VILLAR CRESPO, Guillermo. Comentario a la STC 83/2016: con motivo de la naturaleza de los decretos del gobierno que declaran el estado de alarma. Revista General de Derecho Administrativo. N. 48, 2018. 